

\title{
Investigation on creeping discharges propagating over epoxy resin and glass insulators in the presence of different gases and mixtures
}

\author{
A. Beroual, M.L. Coulibaly, O. Aitken, A. Girodet
}

\section{To cite this version:}

A. Beroual, M.L. Coulibaly, O. Aitken, A. Girodet. Investigation on creeping discharges propagating over epoxy resin and glass insulators in the presence of different gases and mixtures. European Physical Journal: Applied Physics, 2011, 56 (3), pp.30802. 10.1051/epjap/2011110122 . hal-00751655

\author{
HAL Id: hal-00751655 \\ https://hal.science/hal-00751655
}

Submitted on 14 Nov 2012

HAL is a multi-disciplinary open access archive for the deposit and dissemination of scientific research documents, whether they are published or not. The documents may come from teaching and research institutions in France or abroad, or from public or private research centers.
L'archive ouverte pluridisciplinaire HAL, est destinée au dépôt et à la diffusion de documents scientifiques de niveau recherche, publiés ou non, émanant des établissements d'enseignement et de recherche français ou étrangers, des laboratoires publics ou privés. 


\title{
Investigation on Creeping Discharges Propagating over Epoxy Resin and Glass Insulators in Presence of Different Gases and Mixtures
}

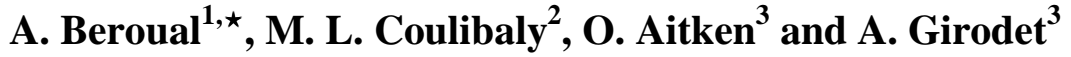 \\ ${ }^{1}$ Ecole Centrale de Lyon, AMPERE CNRS UMR 5005, \\ 36 Avenue Guy de Collongue, 69134 Ecully, France \\ * King Saud University - Distinguished Visiting Professor, \\ Aramco Chair in Electrical Power, Riyadh, Saudi Arabia \\ ${ }^{2}$ ALSTOM Grid Power Transformers, TICC - 129, Avenue de Paris, 91300 Massy, France \\ ${ }^{3}$ ALSTOM Grid - 130, Rue Léon Blum, BP 1321, 69611 Villeurbanne Cedex, France
}

Corresponding author: Abderrahmane.Beroual@ec-lyon.fr

\begin{abstract}
This paper deals with the experimental characterization of discharges propagating over insulators of epoxy and glass, immersed in a gas or a gaseous mixture, under lightning impulse voltages $(1.2 / 50 \mu \mathrm{s})$, using a point-plane electrode arrangement. The gases and mixtures we considered are $\mathrm{SF}_{6}, \mathrm{~N}_{2}, \mathrm{CO}_{2}, \mathrm{SF}_{6}-\mathrm{N}_{2}$ and $\mathrm{SF}_{6}-\mathrm{CO}_{2}$. The morphology of creeping discharges and their final lengths are investigated versus the kind of insulator material, the amplitude and polarity of the voltage, the type of the gas (resp. mixture) and its pressure. It's shown that the shape of discharges and their final (stopping) lengths $L_{f}$ depend significantly on the solid insulator and the type of gas. For given solid and gas, $L_{f}$ increases quasi-linearly with the voltage and decreases when the gas pressure increases. The discharges don't always present a radial structure as reported in literature. For given voltage and pressure, $L_{f}$ is longer when the point electrode is positive than when it's negative while the initiation voltage of discharges is higher with a negative point than with a positive one; and $L_{f}$ is longer with glass than with epoxy. $L_{f}$ is shorter in $\mathrm{SF}_{6}$ than in $\mathrm{CO}_{2}$ or $\mathrm{N}_{2}$. On the other hand, the increase of $\mathrm{SF}_{6}$ content in $\mathrm{SF}_{6}-\mathrm{CO}_{2}$ mixture leads to a significant decrease of $L_{f}$. Therefore the addition of small concentration of $\mathrm{SF}_{6}$ in a given gas mixture improve the dielectric strength of insulating structure.
\end{abstract}

Keywords - creeping discharges, final length, epoxy resin, glass, flashover 


\section{INTRODUCTION}

The solid/gas insulating systems are widely used in high voltage engineering. The dielectric strength of such structures depends on the applied voltage, the properties of solid insulator, the kind of gas as well as the gas pressure and temperature. The behaviour of these insulating structures facing the different stresses and more especially the discharges which can develop within the body of each component (solid or gas) or at the solid/gas interface constitutes one of the main criteria of choice of a given insulating system.

The discharges propagating at gas/solid insulators have been the subject of numerous studies [1 - 3]. However the processes evolved in their development are not yet well understood. Several mechanisms have been proposed to explain the mechanisms implicated in the initiation and propagation of these kinds of discharges. Among these mechanisms, one can cite the dynamic interaction between the discharge and the insulator surface [4 - 6], the accumulation of electrical charge at the insulator surface [7 - 13], the modification of the ionization and attachment coefficient [14, 15] and the distortion of electric field [16, 17]. Therefore, the understanding of the initiation conditions of these creeping discharges and the parameters characterizing their development up to flashover is of great interest for the design and the dimensioning of high voltage components and systems (bushings, insulators, switchgears, gas insulating lines, gas circuit breaker ...).

This paper is aimed at the experimental investigation of creeping discharges propagating over solid insulator issued from epoxy and glass, immersed in a gas or a gas mixture, under lightning impulse voltages $(12 / 50 \mu \mathrm{s})$, using a point-plane electrode arrangement. We especially investigate the morphology of discharges and their final lengths versus the amplitude of the voltage, the type of solid material, the type of gas or gas mixture and pressure.

\section{EXPERIMENT}

The diagram of the experimental setup is given in Figure 1. The test cell containing the considered solid/gas insulating system (gas/solid) and a point-plane electrode arrangement consists of a cylindrical core of $90 \mathrm{~mm}$ high and $110 \mathrm{~mm}$ inner diameter, and two flats and circular covers; the upper cover was of transparent material polymethyl metachrilate (PMMA) enabling to visualize the discharges and to support the sharp electrode; the lower one which constitutes also the electrode plane is a circular plate of $250 \mathrm{~mm}$ diameter and $15 \mathrm{~mm}$ 
thickness, was of brass. The electrode point was made of tungsten with a radius curvature of $10 \mu \mathrm{m}$.

The solid insulating samples we inserted between the electrodes are discs of $100 \mathrm{~mm}$ diameter and $2 \mathrm{~mm}$ thickness. These are made of epoxy resin $\left(\varepsilon_{r}=3.5\right.$ and dielectric strength $E_{d}=22$ $\mathrm{kV} / \mathrm{mm}$ ) and glass $\left(\varepsilon_{r}=5\right.$ and dielectric strength $\left.E_{d}=10 \mathrm{kV} / \mathrm{mm}\right)$. Three gases $\left(\mathrm{N}_{2}, \mathrm{SF}_{6}, \mathrm{CO}_{2}\right)$ and mixtures of these gases $\left(\mathrm{SF}_{6}-\mathrm{N}_{2}\right.$ and $\left.\mathrm{SF}_{6}-\mathrm{CO}_{2}\right)$ are investigated. The solid samples are changed each time we observe irreversible traces on the solid surface that can create preferential ways for the following discharges. A system of taps associated to two manometers enables to fill the test cell and to control the gas pressure. The tests are achieved under lightning impulse voltage $(1.2 / 50 \mu \mathrm{s})$ supplied by a $200 \mathrm{kV}$ Marx generator.

The optical observation of the discharges is based on the integrated images taken with the help of a CCD camera connected to a high performance video card. The CCD camera is a "SONY XCHR58" type, high SVGA resolution (767x580 pixels) image capturing at a speed of 50 full frames/sec. It is set to record 900 images before stopping. During the image grab, the impulse voltage is applied. And thanks to the CCD camera and the video card (Meteor-II/Multi-Channel) to which it's connected, we get the image of the discharge in its maximum extension we called the final length of discharge, $L_{f}$.

\section{EXPERIMENTAL RESULTS}

The initiation threshold voltage $U_{0}$ of creeping discharges, their morphology and final lengths $L_{f}$ mainly depend on the constituents of interface, i.e., the nature of insulator, the amplitude and polarity of the applied voltage, the kind of gas (mixture) and its pressure as well as the concentration of the different constituents of mixtures.

\section{III.1 Initiation threshold voltage of creeping discharges}

We observe that for given interface and gas pressure, the initiation threshold voltage $U_{0}$ are higher when the point is negative than when it's positive. Figure 2 gives an example with glass / SF6 interface. On the other hand, $U_{0}$ is generally higher in $\mathrm{SF}_{6}$ than in $\mathrm{CO}_{2}$ and $\mathrm{N}_{2}$. In these two later gases, the values of $U_{0}$ are too close; it's also the case with $\mathrm{SF}_{6}-\mathrm{CO}_{2}$ and $\mathrm{SF}_{6}$ $\mathrm{N}_{2}$ mixtures. $U_{0}$ is also influenced by the type of the solid insulator material. Indeed, for given gas and pressure, $U_{0}$ is higher with epoxy than with glass whatever the polarity of point. This is due to the enhancement of electric field at the point electrode which is all the higher as the 
difference of dielectric constants between gas and insulator is important (the dielectric constant of glass being higher than that of epoxy).

\section{III.2 Morphology of discharges}

When the applied voltage is higher than $U_{0}$, the discharges (streamers) propagate over the insulator surface by steps as observed by Shibutani et al [18], describing a circular contour around the point electrode. For given interface and gas pressure, the final lengths of discharges are longer with a positive point than with a negative point. Figure 3 gives an example with glass / $\mathrm{SF}_{6}$ interface at $0.2 \mathrm{MPa}$. On the other hand, the shape of discharges is not necessarily radial as reported by numerous researchers (Figure 4); it's clearly different from one polarity to another. The increase of pressure reduces the length of the discharges whatever the interface and polarity of the point electrode (Figures 5 to 7).

The addition of small concentration of $\mathrm{SF}_{6}$ (electronic scavenger additive) to $\mathrm{CO}_{2}$ reduces $L_{f}$. Figure 8 shows the influence of $\mathrm{SF}_{6}$ concentration in $\mathrm{CO}_{2}$ on the final length $L_{f}$. The higher the concentration of $\mathrm{SF}_{6}$, the shorter $L_{f}$ is whatever the polarity of voltage.

\section{III.3 Final length of discharges}

The final lengths of creeping discharges $L_{f}$ is also influenced by the type of solid insulator and the gas as well as the gas pressure. $L_{f}$ increases quasi-linearly with the voltage and decreases when the gas (resp. mixture) pressure is increased (Figures 9 to 15). However, this quasilinearity is not well attended with glass when the point is positive (Figures 13 and 14). This can be due to the fact that: $(i)$ when the discharges propagate over the surface of glass, they leave traces (furrows) that influence the discharge trajectories and then the final lengths [20]; and (ii) the space charge that can modify the electric field and then the propagation of discharges. Note that each point in these figures represents a mean value on at less six measurements. $L_{f}$ is longer with $\mathrm{CO}_{2}$ and $\mathrm{N}_{2}$ than with $\mathrm{SF}_{6}$. Consequently the flashover voltages are lower in $\mathrm{CO}_{2}$ and $\mathrm{N}_{2}$ than in $\mathrm{SF}_{6}$ confirming thus the known dielectric properties (dielectric strength) of this latter with regards to $\mathrm{CO}_{2}$ and $\mathrm{N}_{2}$.

Note that in nitrogen, we observed important scattering of results and especially when the point is positive. Such observations have been already done on the measurements of the dielectric strength of $\mathrm{N}_{2}$ under impulse voltages [23]. At relatively high pressures, the discharges observed in $\mathrm{N}_{2}$ when the point is negative are similar to those obtained in $\mathrm{SF}_{6}$ and $\mathrm{CO}_{2}$. 
The increase of concentration of $\mathrm{SF}_{6}$ in $\mathrm{SF}_{6}-\mathrm{CO}_{2}$ or $\mathrm{SF}_{6}-\mathrm{N}_{2}$ mixtures leads to a decrease of the final length (Figures 12 and 15). However the effect is not very clear with $10 \%$ and $15 \%$ of $\mathrm{SF}_{6}$ in $\mathrm{SF}_{6}-\mathrm{CO}_{2}$ mixture. This can be due to the existence of an optimum concentration of $\mathrm{SF}_{6}$ over which the effect of pressure is not visible. As in pure nitrogen, we also observed an important scattering in the values of $L_{f}$ in presence of $\mathrm{SF}_{6}-\mathrm{N}_{2}$ mixture for different concentrations of $\mathrm{SF}_{6}$. Therefore the use of $\mathrm{N}_{2}$ or $\mathrm{N}_{2}-\mathrm{SF}_{6}$ mixture could present risks for high voltage applications (circuit breakers for instance).

On the other hand, for given gas (mixture) and pressure, $L_{f}$ is longer with glass than with epoxy whatever the polarity of point. This is due to the enhancement of both components (normal and tangential) of electric field which are all the higher as the difference of dielectric constants between gas and insulator is important. Thus, these components especially the tangential one being higher with glass than with epoxy, $L_{f}$ will be longer with glass than with epoxy.

\section{DISCUSSION}

The fact that the positive discharges are longer than the negative ones is due to the physical mechanisms involved in each polarity. When the point is positive, the space charge reduces the field in the vicinity of point but enhances it in the direction of the opposite electrode facilitating the streamers propagation. Thus the streamers can develop at lower voltages than the negative ones. In the case of negative polarity, the space charge reinforces the electric field at the point but reduces it in the direction of the opposite electrode. The streamers slow down and the voltage required to their development will be higher.

On the other hand, for a given pressure and voltage

$$
L_{f}\left(\mathrm{SF}_{6}\right)<L_{f}\left(\mathrm{CO}_{2}\right)<L_{f}\left(\mathrm{~N}_{2}\right)
$$

whatever the polarity. This is due to the dielectric properties of $\mathrm{SF}_{6}$. This latter acts by reducing the ionization phenomena and then the space charges which constitute a major factor influencing the electric field at the head of discharge channels. And the higher the gas pressure the weaker the charge carriers are and the shorter the discharge channels are.

By extrapolating the $L_{f}(\mathrm{U})$ curves (straight lines) at $L_{f}=0$, one can deduce the threshold voltage $U_{0}$ of creeping discharges at a given solid/gas (mixture) interface and pressure. And 
as observed on the light emitted by discharges, $U_{0}$ is higher with negative point than with the positive point. Thus, for a given pressure, the $L f(U)$ characteristics can be described by the following relationship

$$
L_{f}(U)=k_{v}\left(U-U_{0}\right)
$$

$k_{v}$ is a constant depending on both materials constituting the insulation system (solid and gas (type and pressure)). The threshold voltage $U_{0}$ over which a discharge is initiated varies with the pressure and the solid/gas system. It is all the higher as the pressure is high. Tables 1 and 2 summarize the values of initiation threshold voltage $U_{0}$ and slope $k_{v}$ for SF6/epoxy + moulding layer and SF6/glass interfaces, and CO2/epoxy + moulding layer and CO2/glass interfaces respectively versus gas pressure and the polarity of point electrode. Note that $k_{v}$ is higher with a positive point than with a negative one; and it's higher with glass than with epoxy.

The fact that the pressure acts on the discharge reducing their volume, the length and density of their branches indicates the influence of gaseous nature of discharges. The creeping discharges propagating over epoxy with moulding layer present a maximal extension $\left(L_{f}\right)$ relatively higher than that measured with polytetrafluoroethylene filled with mineral fillers in the same experimental conditions [19]. It appears that, for a given voltage, there is a pressure for which any discharge can appear as we reported for solid/liquid interface [20 - 22]. Therefore the increase of gas pressure enables to improve the dielectric strength of a given solid/gas (mixture) insulating system.

\section{CONCLUSION}

This study shows that the discharges pattern and final length, $L_{f}$, of creeping discharges depend on the amplitude and polarity of the voltage, the kind and pressure of gas, the constituents of gas mixture and the solid sample. The initiation threshold voltage $U_{0}$ is higher with a negative point than with a positive one; and it's higher with epoxy than with glass. For given gas (mixture) and pressure, $L_{f}$ is longer with glass than with epoxy whatever the polarity of point.

For a given gas or mixture, the final length of discharges $L_{f}$ generally increases quasi-linearly with the voltage; it's reduced when the pressure is increased. 
$L_{f}$ is shorter in $\mathrm{SF}_{6}$ than in $\mathrm{CO}_{2}$ or $\mathrm{N}_{2}$. And the addition of small content of electronegative gas reduces $L_{f}$ and thence improves the dielectric strength of the insulating structure. $L_{f}$ is higher with a positive point electrode than with a negative one indicating thus that the penalising polarity is the positive one. This is of a great interest for the dimensioning of electrical apparatus with gaseous insulation. In $\mathrm{N}_{2}$, the values of $L_{f}$ present a significant scattering from one shoot to another. This constitutes a risk if one has to use $\mathrm{N}_{2}$ or $\mathrm{SF}_{6}-\mathrm{N}_{2}$ mixture in high voltage apparatus.

\section{REFERENCES}

[1] T. S. Sudarsham and R. Dougal, "Mechanisms of surface flashover along solid dielectrics in compressed gases", Review, IEEE Trans. of Electr. Insul., No. 21, p. 727-746, 1986.

[2] C. X. Wang, A. Wilson and M. W. Watte, "Surface charge flashover sustained by electrostatic surface charge on epoxy resin insulator in $S F_{6} "$, IEE Proc., A Sci. meas. techno. Vol. 140, No. 5, p. 346-350, 1993.

[3] I. Al Bawy and O. Farish, "Insulator flashover in $S_{6}$ under impulse voltage conditions", IEE Proc. A, Vol. 138, p. 89-97, 1991.

[4] N. L. Allen and B. H. Tan, "Initiation of positive corona on insulator surface". Proc. of the $12^{\text {th }}$ Int. Symp. on High Voltage Engineering., Bangalore, India, Vol. 3, p. 5-8, 2001.

[5] N. L. Allen and P. N. Mikropulos, "Streamer propagation along insulating surfaces in air", IEEE Trans. Electr. Insul., Vol. 6, No. 3, p. 357-362, 1999.

[6] M. Akyuz, L. Gao, V. Cooray, T. G. Gustavsson, S. M. Gubanski and A. Larsson, "Positive streamer discharge along insulating surface", IEEE Trans. Electr. Insul., Vol. 8, No. 6, p. 902-910, 2001.

[7] N. L. Allen and D. C. Faircloth, "Corona propagation and charge deposition on a PTFE surface", IEEE Trans. Electr. Insul., Vol. 10, No. 2, pp. 295-304, 2003.

[8] T. Jing, "Surface charge accumulation: an inevitable phenomenon in DC GIS", IEEE Trans. Electr. Insul., Vol. 2, No. 5, p. 771-778, 1995.

[9] K. D. Srivastava and J. Zhou, "Surface charging and flashover of spacers in $\mathrm{SF}_{6}$ under impulse voltages", IEEE Trans. Electr. InsuL, Vol. 26, No. 3, p. 428- 442, 1991.

[10] K. Nakanishi, A. Yoshioka, Y. Shibuya and T. Nitta, "Charge accumulation on spacer surface at DC stress in compressed $S_{6}$ gas", Gaseous Dielectrics III, Edition Pergamon, New York, USA, p. 365-373, 1982. 
[11] H. Fujinami, T. Takuma, M. Yashima, T. Kawamoto, "Mechanism and effect of DC charge accumulation on $S_{6}$ gas insulated spacers", IEEE Trans. Electr. InsuL, Vol. 22, p. 333-340, 1987.

[12] A. Knecht, "Development of surface charge accumulation on epoxy resin spacers stressed with direct applied voltage", Gaseous Dielectrics III, Edition Pergamon, New York, USA, p. 356-364, 1982.

[13] R. A. Fouracre, F. A. Twema, S. J. MacGregor and M. J. Given, "The influence of charge on surface flashover", $11^{\text {th }}$ Int. Symp. on High Voltage Engineering., No. 467, Vol. 3, p. 329$332,1999$.

[14] I. Gallimbertti, I. Marchesi and L. Niemeyer, "Streamer corona at an insulating surface", Proc. of $7^{\text {th }}$ Int. Symp. on High Voltage Engineering., Dresden, Germany, p. 1-4, 1991.

[15] N. L. Allen and A. A. R. Hashem, "The role of negative ions in the propagation of discharges across insulating surfaces", J. Phys. D. Appl. Phys., Vol. 35, p. 2551-2557, 2002.

[16] S. Sato, W. S. Zaengl and A. Knecht, "A numerical analysis of accumulated surface charge on DC epoxy resin spacer", IEEE Trans. Electr. Insul., Vol. 22, p. 333- 340, 1987.

[17] T. Jing and P. H. F. Morshuis, "Evaluation of Field-steering Techniques in GIS with Respect to Surface Charge Accumulation", Proc. of $4^{\text {th }}$ Int. Conf. on Conduction and Breakdown in Solid Dielectrics, Sestri Levante, Italy, p. 102-106, 1992.

[18] D. Shibutani H. Naoki and H. Okubo, "Impulse Creepage Discharge Propagation Mechanisms in N2/SF6 Gas Mixtures" Trans. of the Institute of Elect. Eng. of Japan, Vol.121B, $\mathrm{N}^{\circ} 4$, pp. 455 - 460, 2001.

[19] M. L. Coulibaly and A. Beroual, O. Aitken and A. Girodet, "Investigation on Creeping Discharges Propagating over Insulators Immersed in Gases and Gas Mixtures under Lightning Impulse Voltage", 2008 International Conference on High Voltage Engineering and Application, Chongqing, China, $9^{\text {th }}-12^{\text {th }}$ November, 2008.

[20] L. Kebbabi and A. Beroual, "Optical and Electrical Investigations on Creeping Discharges over Solid / Liquid Interface under Lightning Impulse Voltage", IEEE Trans. Dielectrics and Electrical Insulation, Vol. 13, No. 3, 2006, pp. 565-571.

[21] L. Kebbabi and A. Beroual, "Influence of solid insulating thickness on the morphology of creeping discharges propagating over solid/liquid interfaces - Fractal analysis", J. of Physics D: Applied Physics 39 (2006), pp. 177-183.

[22] A. Beroual and L. Kebbabi, "Influence of the Voltage Waveform and Hydrostatic Pressure on Morphology of Final Length of Discharges Propagating over Solid/Liquid 
Interfaces", IEEE Trans. Dielectrics and Electrical Insulation, Vol. 16, No 6, 2009, pp. 15741581.

[23] M. L. Coulibaly, "Caractérisation des décharges électriques se propageant aux interfaces gaz / solide - Relation entre propriétés des matériaux et dimension fractale", $\mathrm{PhD}$ Thesis, Ecole Centrale de Lyon, France, 2009. 
Table 1: Values of initiation threshold voltage $U_{0}$ and slope $k_{v}$ for SF6/epoxy + moulding layer and SF6/glass interfaces versus gas pressure and polarity of point electrode.

\begin{tabular}{|c|c|c|c|c|c|c|c|c|c|}
\hline Gas pressure (MPa) & \multicolumn{2}{|c|}{0.05} & \multicolumn{2}{c|}{0.1} & \multicolumn{2}{c|}{0.15} & \multicolumn{2}{c|}{0.2} \\
\hline Voltage polarity & + & - & + & - & + & - & + & - \\
\hline Interface & \multicolumn{8}{|c|}{ SF6/Epoxy+moulding layer } \\
\hline$U_{0}(\mathrm{kV})$ & 25.5 & 25.9 & 26.7 & 30.7 & 30.0 & 33.7 & 30.8 & 36.0 \\
\hline$k_{v}(\mathrm{~mm} / \mathrm{kV})$ & 3.6 & 1.17 & 2.6 & 1.17 & 3 & 1.16 & 3 & 1.15 \\
\hline Interface & \multicolumn{8}{|c|}{ SF6/Glass } \\
\hline$U_{0}(\mathrm{kV})$ & 18.0 & 19.5 & 20.4 & 21.3 & 23 & 23.6 & 24 & 28.0 \\
\hline$k_{v}(\mathrm{~mm} / \mathrm{kV})$ & 6.8 & 3.8 & 7.0 & 3.8 & 7.0 & 3.8 & 7.0 & 3.8 \\
\hline
\end{tabular}

Table 2: Values of initiation threshold voltage $U_{0}$ and slope $k_{v}$ for $\mathrm{CO} 2 /$ epoxy + moulding layer and $\mathrm{CO} 2 /$ glass interfaces versus gas pressure and polarity of point electrode.

\begin{tabular}{|c|c|c|c|c|c|c|c|c|c|c|l|l|}
\hline Gas pressure (MPa) & \multicolumn{2}{|c|}{0.1} & \multicolumn{2}{c|}{0.2} & \multicolumn{3}{c|}{0.3} & \multicolumn{3}{|c|}{0.4} & \multicolumn{2}{|c|}{0.5} \\
\hline Voltage polarity & + & - & + & - & + & - & + & - & + & - \\
\hline Interface & \multicolumn{8}{|c|}{ CO2/Epoxy+moulding layer } \\
\hline$U_{0}(\mathrm{kV})$ & 19.0 & 33 & 22.3 & 34 & 23.5 & 38 & 24.5 & 41 & 27.0 & 42 \\
\hline$k_{v}(\mathrm{~mm} / \mathrm{kV})$ & 4 & 2.1 & 3 & 1.9 & 3 & 1.8 & 2.9 & 1.8 & 2.9 & 1.8 \\
\hline Interface & \multicolumn{10}{|c|}{ CO2/Glass } \\
\hline$U_{0}(\mathrm{kV})$ & 16.0 & 22.6 & 16.7 & 26 & 17.0 & 28 & 18.6 & 29.0 & 19.3 & 31.5 \\
\hline$k_{v}(\mathrm{~mm} / \mathrm{kV})$ & 8.3 & 5 & 7 & 5 & 5.3 & 4 & 6.7 & 4.1 & 6.7 & 3.2 \\
\hline
\end{tabular}




\section{Figures}

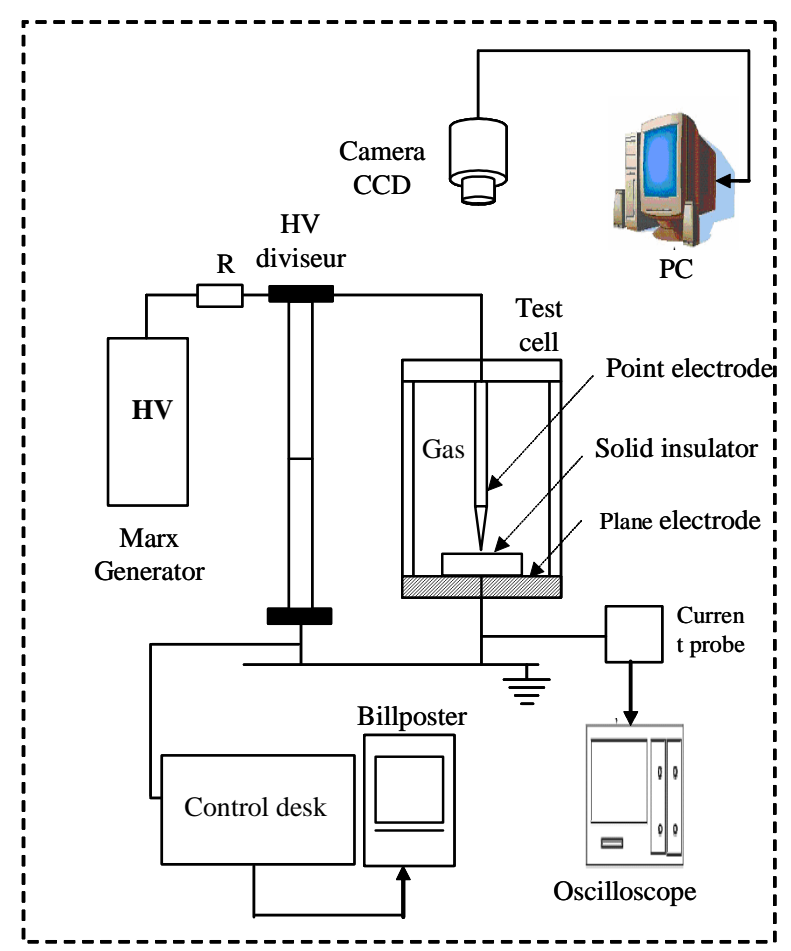

Figure 1. Scheme of experimental setup 


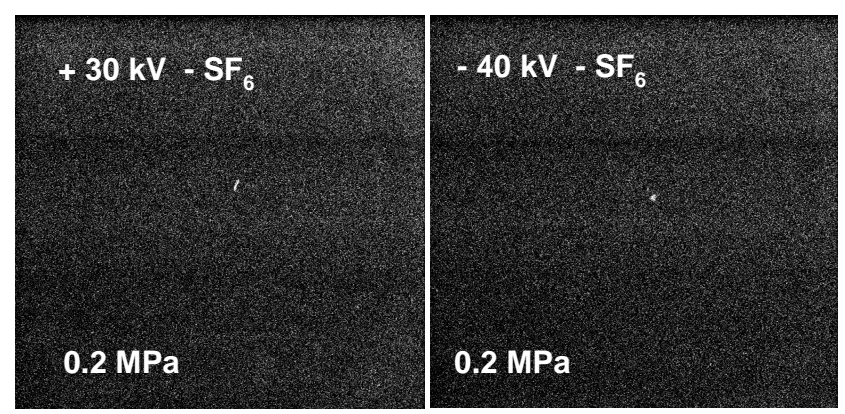

Figure 2. Comparison of the positive and negative initiation threshold voltages of creeping discharges for epoxy resin $/ \mathrm{SF}_{6}$ interface at $0.2 \mathrm{MPa}$

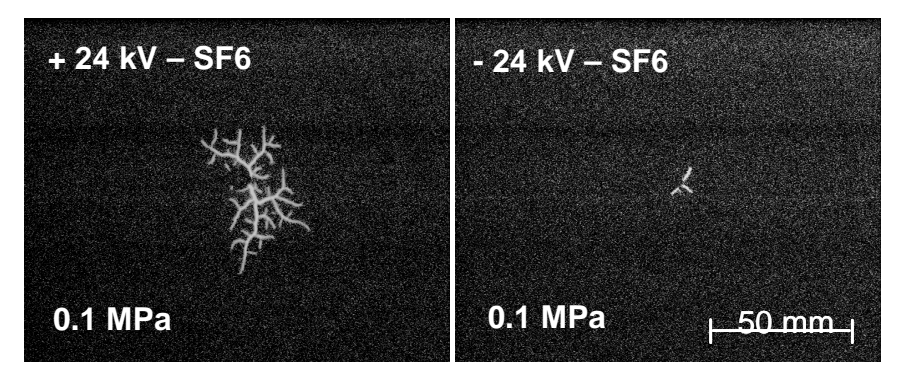

Figure 3. Influence of the polarity of voltage and gas pressure on the final length of discharges propagating over glass $/ \mathrm{SF}_{6}$ interface
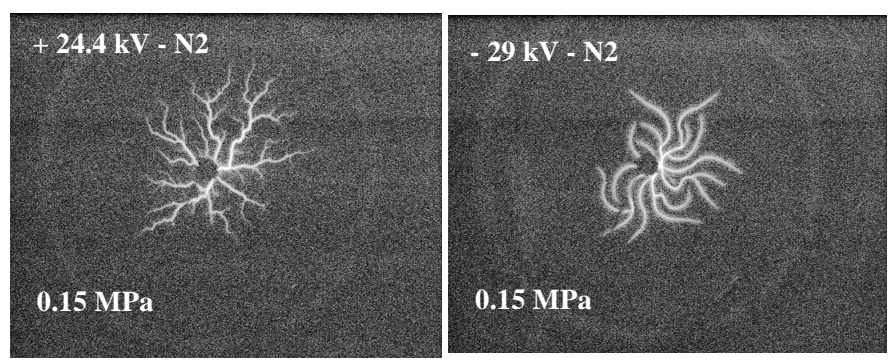

Figure 4. Morphology of positive and negative discharges propagating over glass / $\mathrm{N}_{2}$ interface at a pressure of $0.15 \mathrm{MPa}$ 


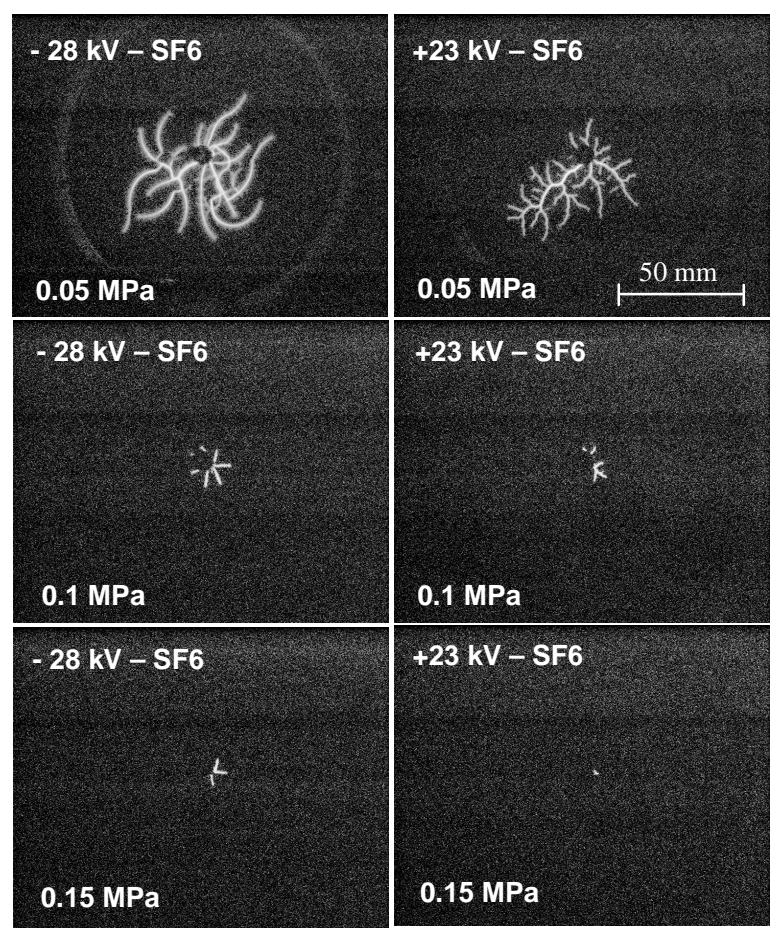

Figure 5. Influence of gas pressure and polarity of voltage on the final length of discharges propagating over a glass $/ \mathrm{SF}_{6}$ interface

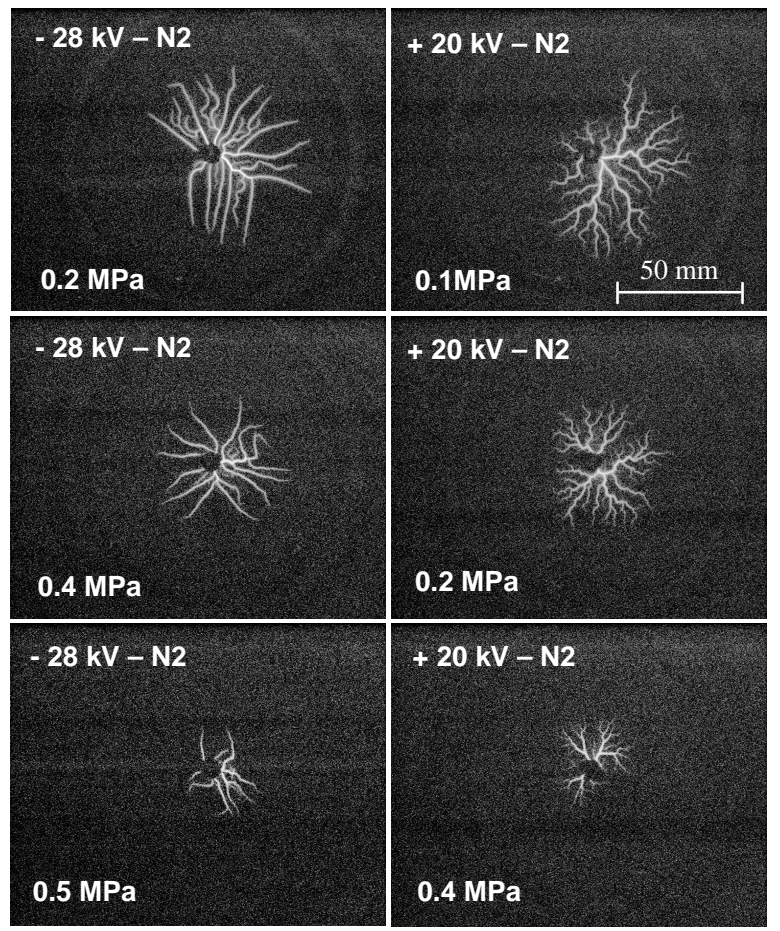

Figure 6. Influence of gas pressure and polarity of voltage on the final length of discharges propagating over a glass $/ \mathrm{N}_{2}$ interface 


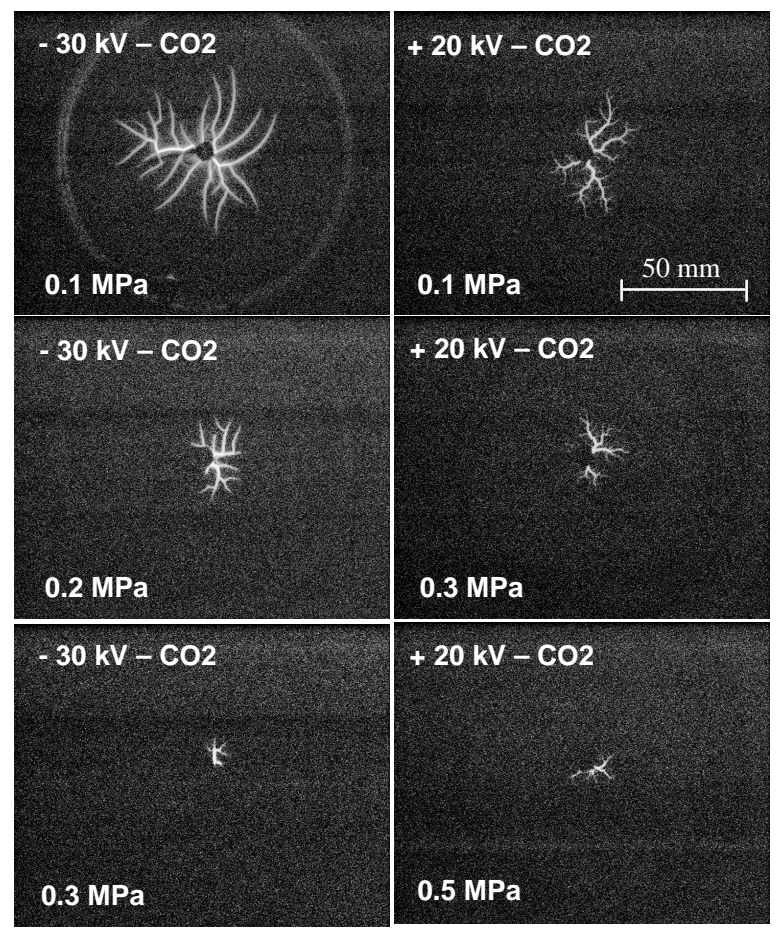

Figure 7. Influence of gas pressure and polarity of voltage on the final length of discharges propagating over a glass $/ \mathrm{CO}_{2}$ interface

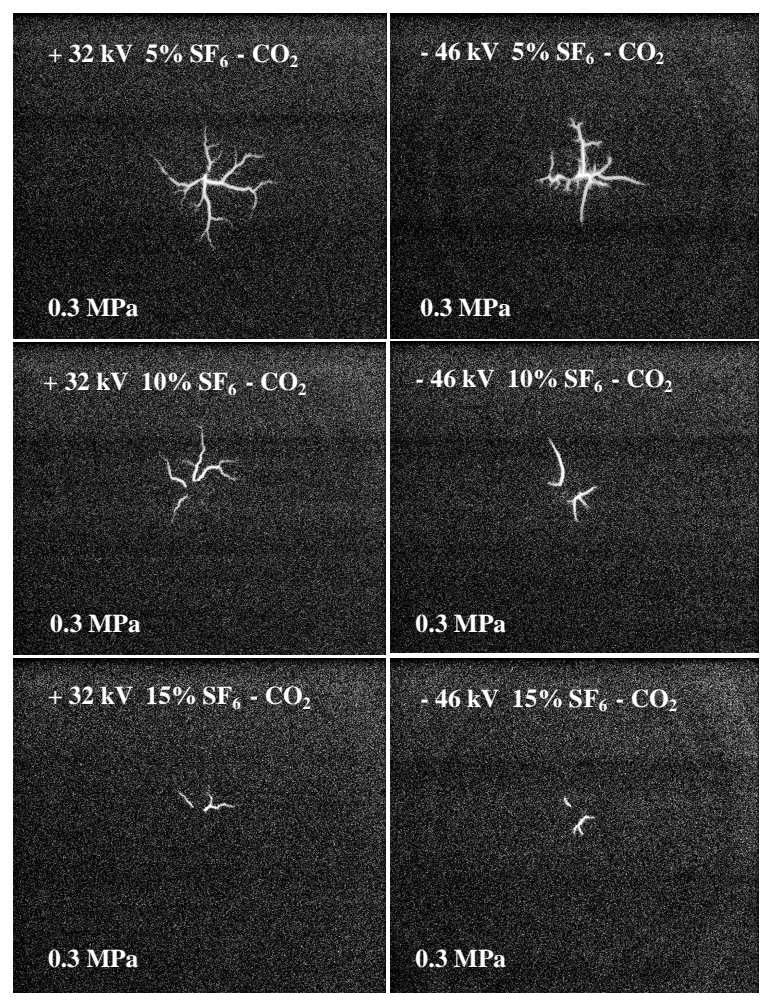

(a)

(b)

Figure 8. Influence of $\mathrm{SF}_{6}$ content in $\mathrm{CO}_{2}$ at $0.3 \mathrm{MPa}$ on creeping discharges propagating over epoxy resin for both polarities: (a) positive and (b) negative 


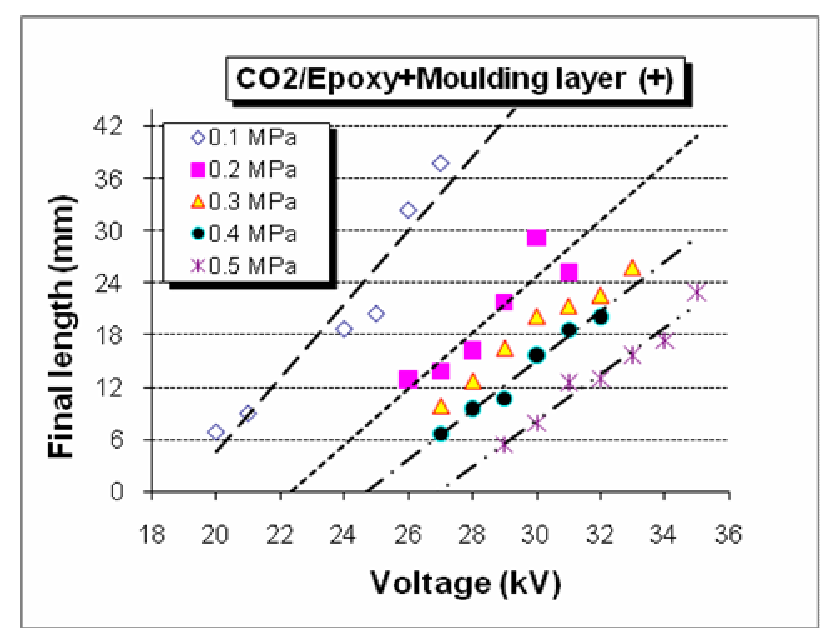

(a)

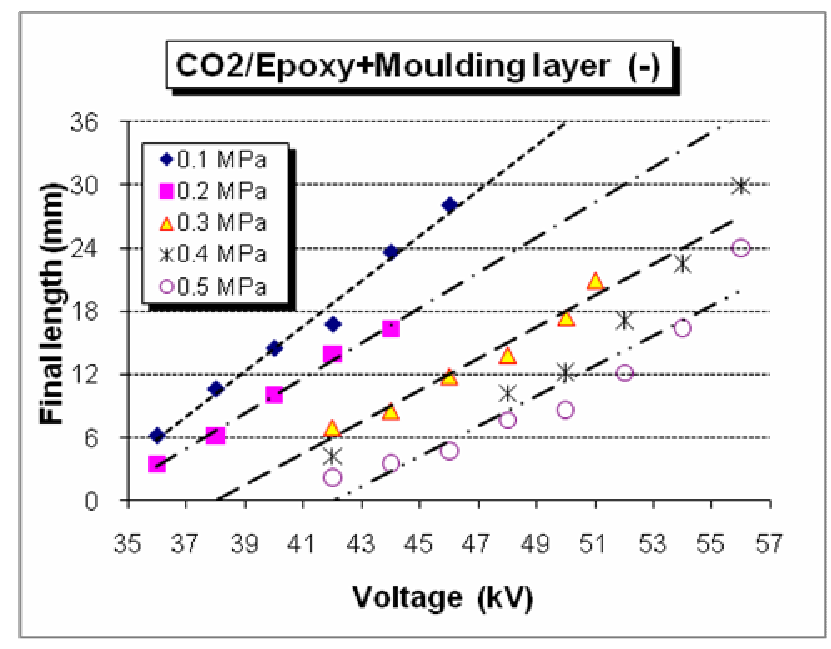

(b)

Figure 9. Final length of creeping discharges over epoxy resin immersed in $\mathrm{CO}_{2}$ versus the voltage for positive and negative point and for different pressures 


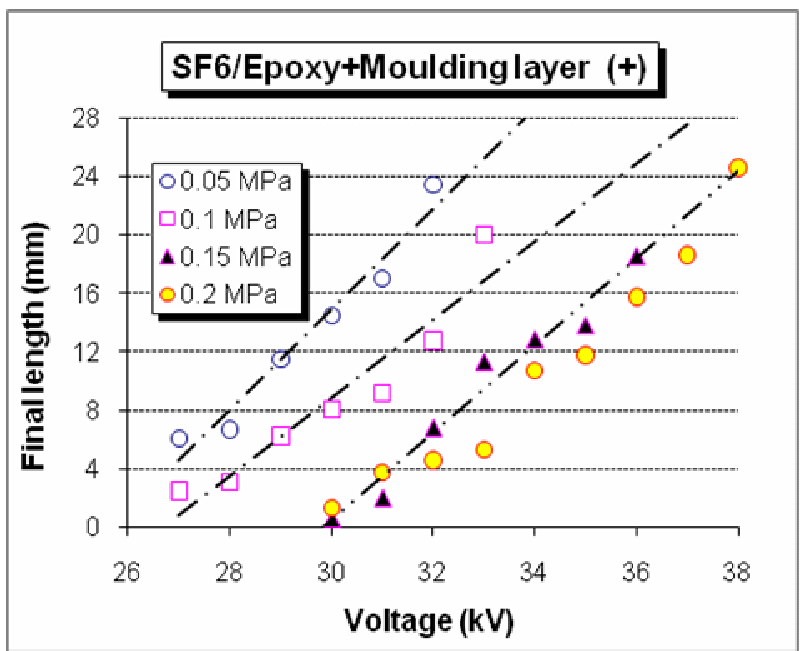

(a)

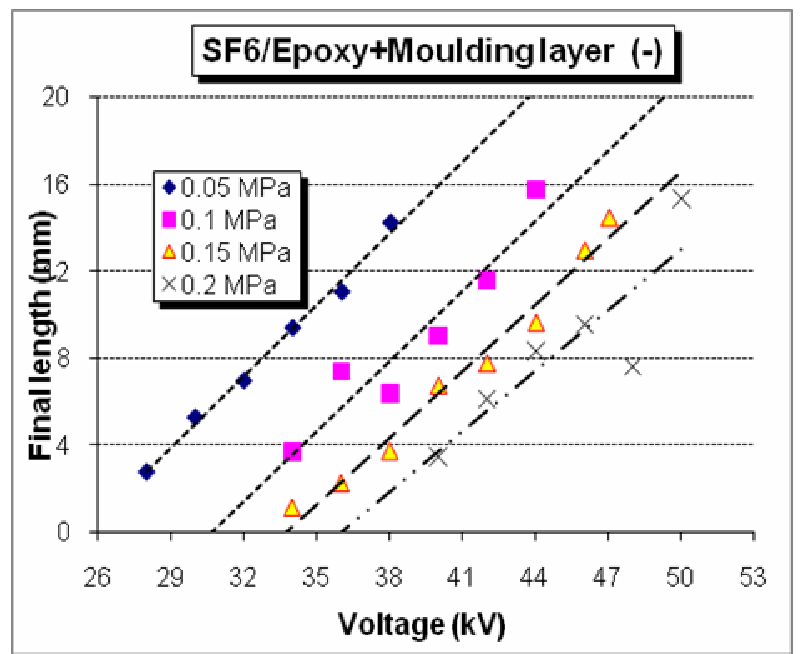

(b)

Figure 10. Final length of creeping discharges over epoxy resin immersed in $\mathrm{SF}_{6}$ versus the voltage for positive and negative point and for different pressures 


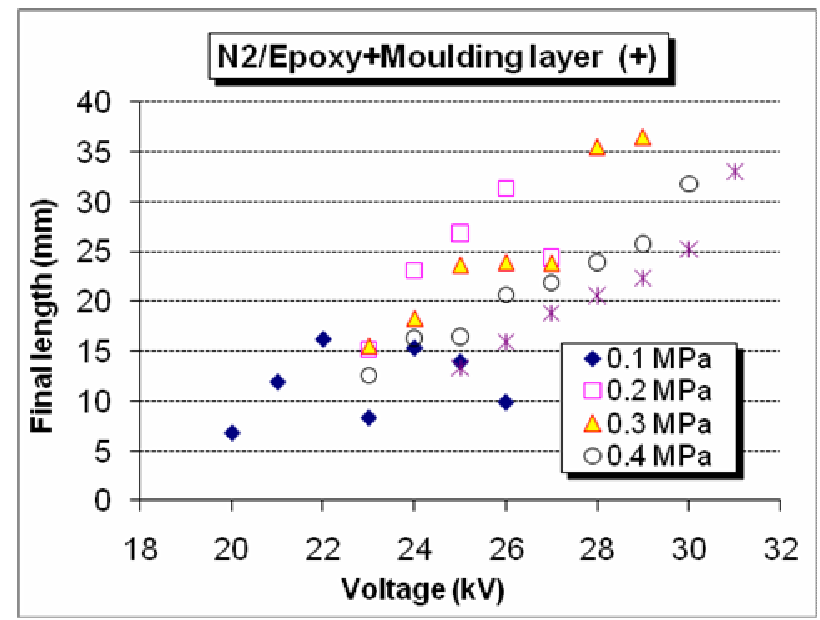

(a)

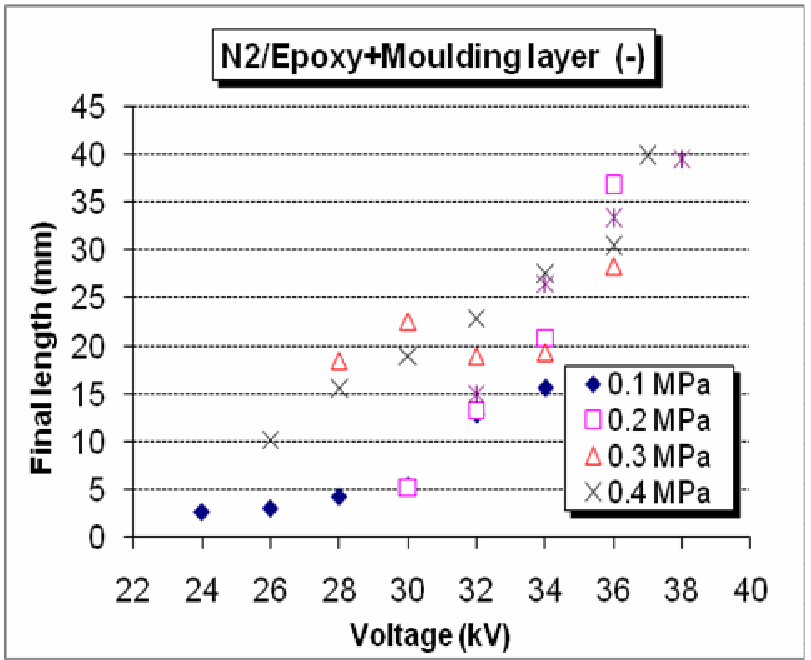

(b)

Figure 11. Final length of creeping discharges over epoxy resin immersed in N2 versus the voltage for positive and negative point and for different pressures. 


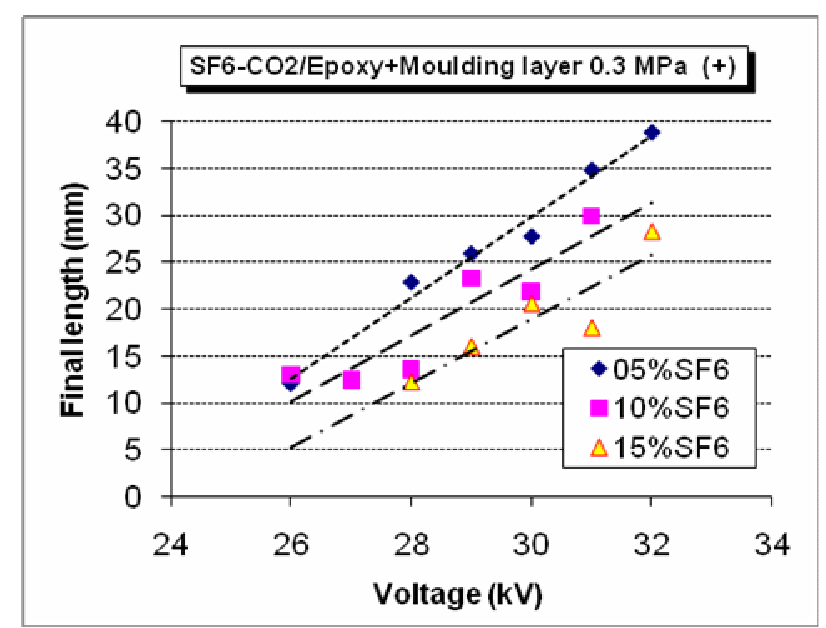

(a)

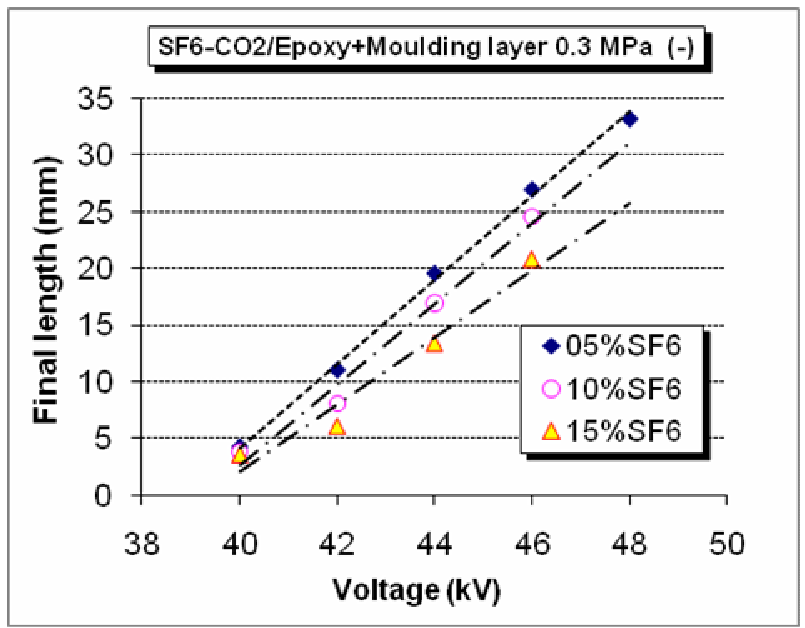

(b)

Figure 12. Final length of creeping discharges over epoxy resin immersed in CO2-SF6 mixtures at $0.3 \mathrm{MPa}$ versus the voltage for positive and negative point and for different pressures: (a) positive polarity, (b) negative polarity 

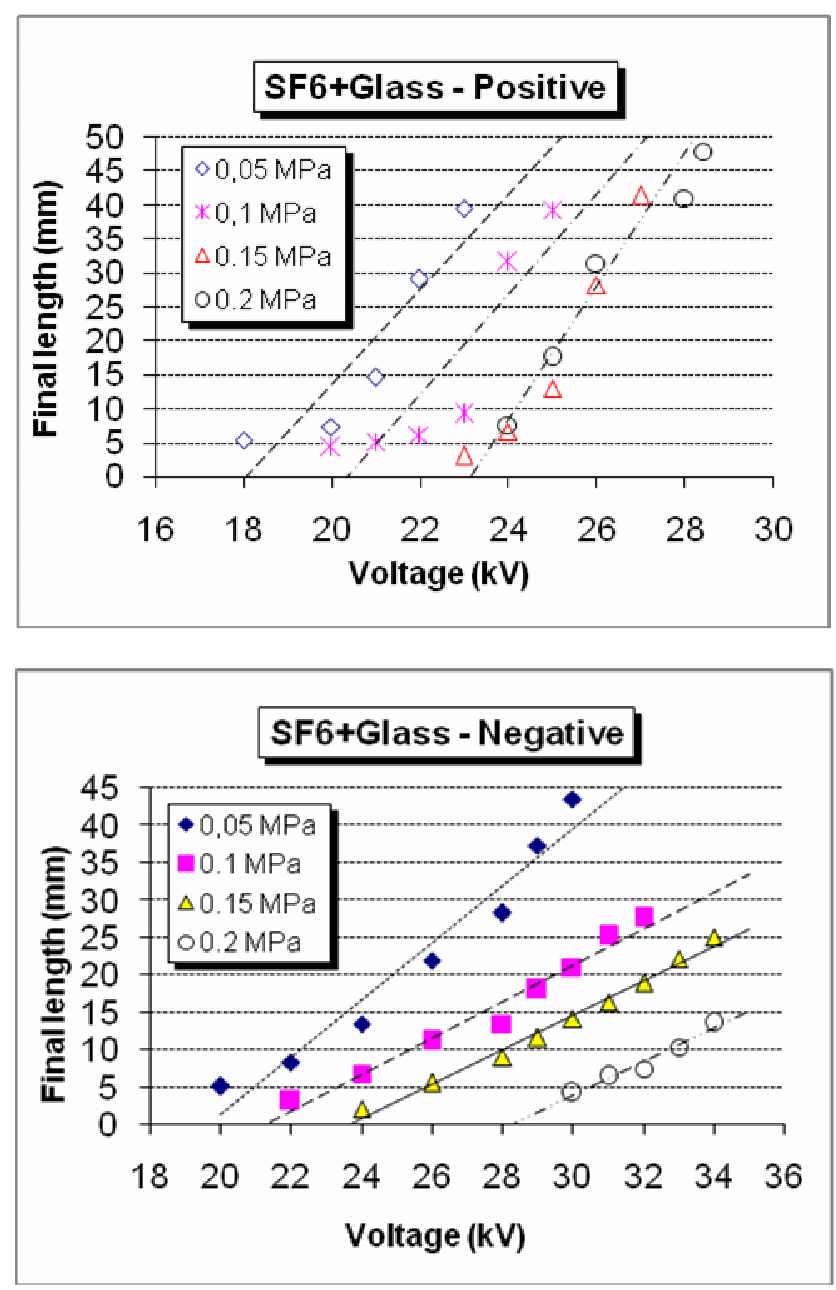

Figure 13. Evolution of the final length versus the voltage in $\mathrm{SF}_{6}$ for both polarities and for different pressures 

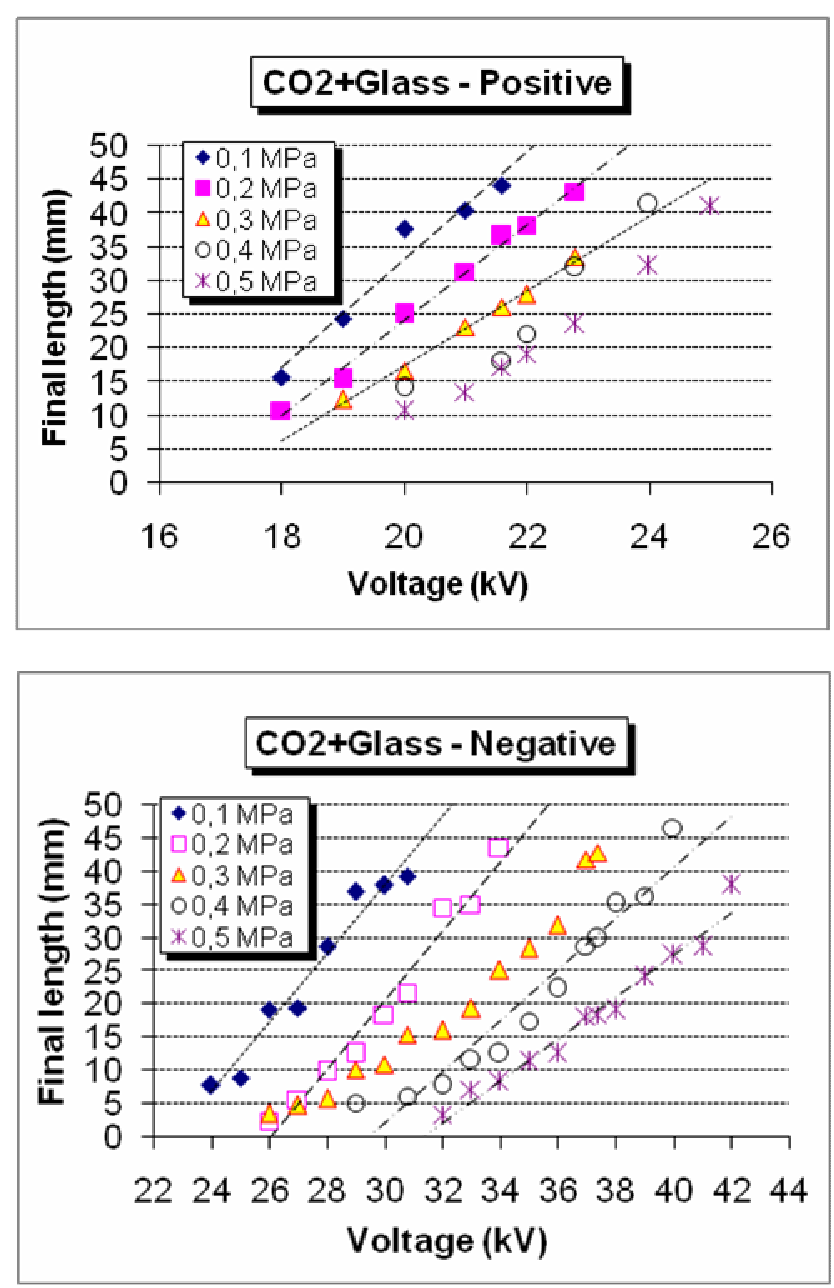

Figure 14. Evolution of the final length versus the voltage in $\mathrm{CO}_{2}$ for both polarities and for different pressures 

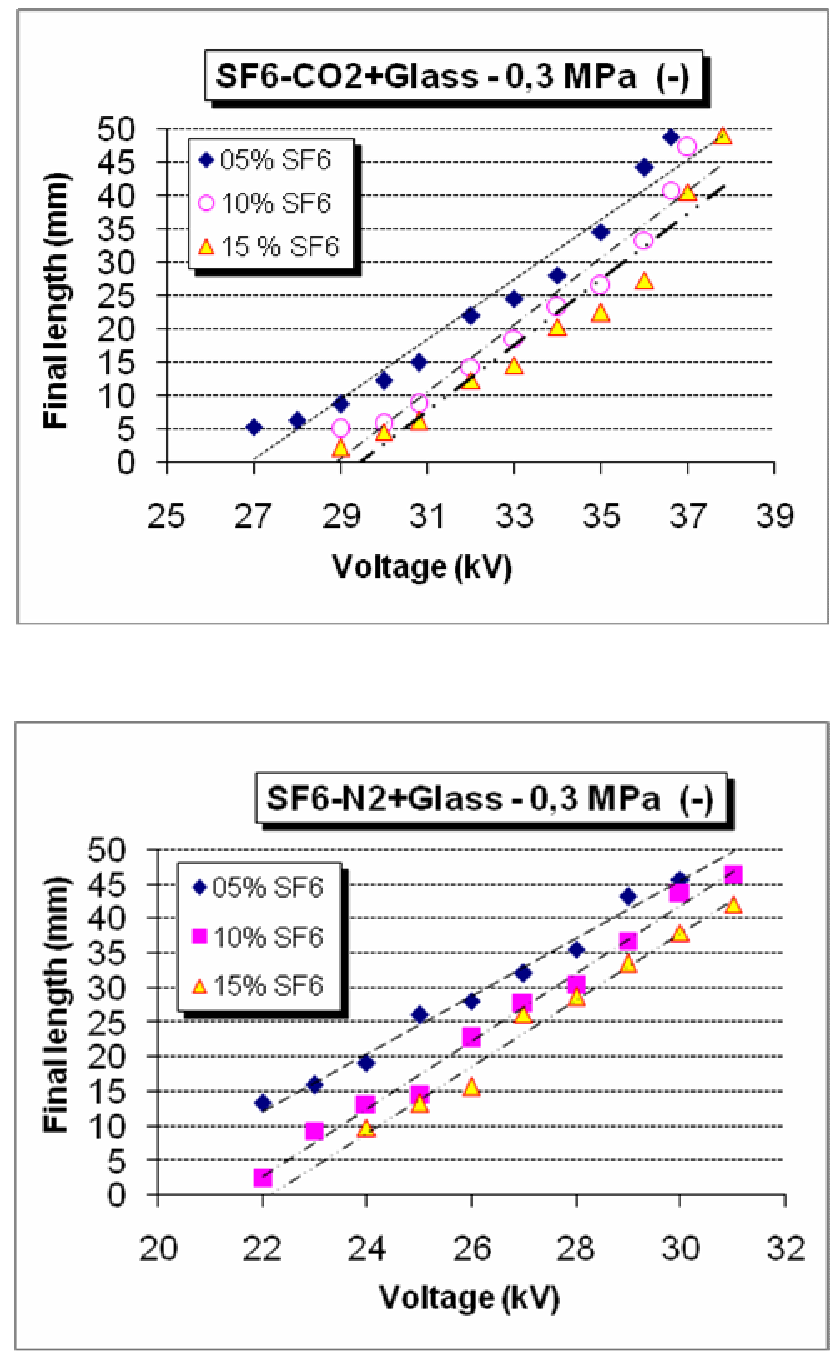

Figure 15. Evolution of the final length versus the voltage in $\mathrm{SF}_{6}-\mathrm{CO}_{2}$ and $\mathrm{SF}_{6}-\mathrm{N}_{2}$ mixtures for a negative point and for different pressures 